\title{
Unha achega á historia da edición en Galiza: Lugo nos anos do franquismo
}

\author{
A Contribution to the History of Publishing in Galicia: \\ Lugo during the Franco Regime
}

\author{
Carme Fernández Pérez-Sanjulián \\ Universidade da Coruña \\ Departamento de Galego-Portugués, Francés e Lingüística \\ carme@udc.gal
}

[recibido 03/12/2014, aceptado 26/01/2015]

\section{RESUMO}

A actividade editorial na Galiza durante o franquismo foi máis ampla e diversificada do que habitualmente se considera. A modo de exemplo, analízase neste traballo a produción e os axentes editoriais que desenvolveron o seu labor na cidade de Lugo no período que se estende de 1939 a 1975. Esta achega confirma a heteroxeneidade das iniciativas, empresas e axentes implicados.

PALABRAS CHAVE: Franquismo, Galiza, produción editorial, Lugo.

\section{RESUMEN}

La actividad editorial en Galicia durante el franquismo fue mas amplia y diversificada de lo que habitualmente se considera. A modo de ejemplo, se analiza en este trabajo la producción y los agentes editoriales que desarrollaron su trabajo en la ciudad de Lugo en el período que se extiende desde 1939 a 1975. Esta contribución confirma la heterogeneidad de las iniciativas, empresas y agentes implicados.

PALABRAS CLAVE: Franquismo, Galicia, producción editorial, Lugo.

\section{ABSTRACT}

Publication in Galicia during the Franco regime was more prevalent and varied than what is usually believed. This article examines output from publishings in the city of Lugo during the period 1939-1975. The study confirms the range and diversity of initiatives, businesses and individuals involved.

KEY WORDS: Franquism, Galiza, publisher production, Lugo.

FERnÁNDEZ PÉREZ-SAnjulián, C. (2015): "Unha achega á historia da edición en Galiza: Lugo nos anos do franquismo", Madrygal (Madr.), 18, Núm. Especial: 443-456.

SUMARIO: 1 . Introdución. 2. Empresas con iniciativas de carácter editorial. 2.1. Ediciones Celta. 2.2. Imprentas e librarías: Gerardo Castro, Palacios, Gráficas Bao, Alvarellos, La Voz de la Verdad. 2.3. Cartonajes Anmi. 3. Outros axentes e iniciativas editoriais. 3.1. Coleccións Xistral e Ronsel. 3.2. Círculo das Artes de Lugo. 4. Conclusións. 5. Referencias bibliográficas. 


\section{INTRODUCIÓN}

Á hora de analizarmos a actividade editorial na Galiza durante o período que se estende de 1939 a $1975^{1}$, constatamos que, de máis a máis, dispomos dalgúns traballos centrados no labor dos editores máis relevantes (Xosé $\mathrm{M}^{\mathrm{a}}$ Álvarez Blázquez, Francisco Fernández del Riego, Ramón Piñeiro ou, en menor medida, sobre Isaac Díaz Pardo) ou, mesmo, na análise da actividade dalgunhas editoras, nomeadamente da editorial Galaxia que, polo seu carácter central, foi a que concitou máis atención crítica. Ao tempo, obsérvase tamén que son bastantes os proxectos editoriais sobre os que existen escasas análises rigorosas, o que pon en evidencia que o período carece aínda dun estudo de conxunto, sistemático e exhaustivo.

Neste sentido, é importante subliñar que a revisión da produción editorial da época revela, entre outros datos, a existencia de heteroxéneos axentes actuantes (editoras comerciais e institucionais, librarías, promotores diversos, imprentas...) e unha extensa distribución espacial dos mesmos ao longo de toda a Galiza, factores que non foron tidos en conta suficientemente á hora de analizar o mundo cultural e editorial desta etapa. Falta, pois, por realizar unha descrición pormenorizada de todos eses axentes e da súa actividade, de modo que posibilite a análise en profundidade dos proxectos editoriais activos na Galiza da posguerra, tanto nos aspectos ideolóxico-culturais como comerciais, para, deste xeito, os comparar entre si e poñer en relevo a súa influencia individual e colectiva na reactivación posterior da cultura galega.
En concreto, na liña de fornecermos datos para ese traballo exhaustivo aínda pendente, neste artigo centrarémonos no estudo de un caso especialmente relevante, o da cidade de Lugo, cunha recoñecida vida cultural e de compromiso galeguista, onde se vai xerar unha ampla produción editorial ao longo do período franquista. Así, achegarémonos ao catálogo de Ediciones Celta, mais tamén a outras iniciativas culturais como a Revista e Colección de poesía Xistral ou a Colección Ronsel; ás publicacións do Círculo das Artes e, mesmo, ás dun axente editorial pouco coñecido: Cartonaxes Anmi. Ao tempo, revisaremos o labor editorial de varias imprentas activas no período analizado: Bao, Gerardo Castro, La Voz de la Verdad ou Alvarellos.

\section{EMPRESAS CON INICIATIVAS DE CARÁCTER EDITORIAL}

\subsection{EDICIONES CELTA}

Á hora de describirmos un panorama da vida editorial no Lugo daqueles anos, esta editora merece unha especial atención pois son múltiplos os testemuños que insisten no seu papel de referente, por ser quen mantivo a difusión da cultura galega de forma firme e constante ${ }^{2}$.

Ediciones Celta, creada en Lugo como imprenta en 1938 polo madrileño Francisco Esteban González, e asociada á libraría do mesmo nome ${ }^{3}$, comezou a editar en 1939 (o seu primeiro título foi El correo de los enamorados, de Adela Díaz González, asinado sob o pseudónimo de Luís López), e xa continuou cunha actividade editora constante nos anos

\footnotetext{
${ }^{1}$ Este traballo está realizado ao abeiro de dous proxectos complementares: "La producción editorial en Galicia durante la etapa franquista (1939-1975)" (FFI2010-16924) e "Produción e mercado editorial en Galiza durante a etapa franquista: a súa incidencia na industria editorial actual" (10SEC104017PR). Os resultados parciais do proxecto (información, a Base de Datos que recolle a produción editorial en formato de libro publicada na Galiza na etapa e parte das entrevistas realizadas) pódense ver en: http://ediciongaliciafranquista.udc.es/.

${ }^{2}$ Sinálano, entre outros, Alvarellos Casas (2014), Gómez Torres (2001: 104) ou Saleta Goi (entrevista inédita, 22/11/2014).

${ }^{3}$ A Libraría Celta nace cara ao 1933 na Rúa da Raíña, mais en 1939 trasládase á súa ubicación definitiva na Rúa de San Marcos de Lugo (Reboredo 2011: 110).
} 
seguintes. Intercalaba publicacións literarias varias (entre as que cumpriría subliñar un auténtico best-seller da época: Supersticiones de Galicia y preocupaciones vulgares, de Xesús Rodríguez López, que chegou a reeditarse cinco veces), con publicacións técnicas, como os manuais de tráfico e os textos de diferentes leis e decretos do estado, que son os que axudarían a manter unha actividade editorial que chega aos cento corenta e catro títulos no período que vai de 1939 a 1975, dos cales trinta e tres son libros en lingua galega (véxase Tabela 1).

Nos primeiros anos de actividade, ademais das publicacións con lexislación de todo tipo (La contribución excepcional sobre beneficios extraordinarios de guerra ou Ley y Reglamento sobre el régimen obligatorio de subsidios familiares), a editorial publica traballos como Filosofía. Primer curso, do catedrático

\begin{tabular}{|c|c|c|c|}
\hline Obra & Autoría & Tipo & Xénero \\
\hline $\begin{array}{l}\text { Contos en cuarto crecente } \\
1^{\text {a }} \text { ed. Lugo: Ediciones Celta, } 1952 \\
2^{\text {a }} \text { ed. corrix. e aumentada Lugo: Ediciones Celta, } 1962\end{array}$ & Manuel María & Libro & Narrativa \\
\hline $\begin{array}{l}\text { Terra Cha } \\
1^{\text {a }} \text { ed. Lugo: Ediciones Celta, } 1954 \\
3^{\text {a }} \text { ed. Lugo: Ediciones Celta, } 1972\end{array}$ & Manuel María & Libro & Poesía \\
\hline $\begin{array}{l}\text { Documentos personaes } \\
1^{\mathrm{a}} \text { ed. Lugo: Ediciones Celta, } 1958 \\
2^{\mathrm{a}} \text { ed. Lugo: Ediciones Celta, } 1970\end{array}$ & Manuel María & Libro & Poesía \\
\hline $\begin{array}{l}\text { Contribución ao estudo das fontes literarias de Rosalia } \\
1^{\mathrm{a}} \text { ed. Lugo: Ediciones Celta, } 1959\end{array}$ & Ricardo Carballo Calero & Libro & Ensaio \\
\hline $\begin{array}{l}\text { Libro de Pregos } \\
1^{\text {a }} \text { ed. Lugo-Madrid: Ediciones Celta, } 1962\end{array}$ & Manuel María & Libro & Poesía \\
\hline $\begin{array}{l}\text { Retrincos } \\
2^{\mathrm{a}} \text { ed. Lugo-Madrid: Ediciones Celta, } 1962 \\
4^{\mathrm{a}} \text { ed. Lugo: Ediciones Celta, } 1971\end{array}$ & Alfonso Daniel R. Castelao & Libro & Narrativa \\
\hline $\begin{array}{l}\text { Textos literarios sobre Lugo y su provincia } \\
1^{\text {a }} \text { ed. Lugo: Ediciones Celta, } 1963\end{array}$ & $\begin{array}{l}\text { Xesús Alonso Montero } \\
\text { Enrique Santín Díaz (sel.) }\end{array}$ & Libro & \\
\hline $\begin{array}{l}\text { Palabra no tempo: } 1958-1963 \\
1^{\text {a }} \text { ed. Lugo: Ediciones Celta, } 1963\end{array}$ & María Mariño Carou & Libro & Poesía \\
\hline $\begin{array}{l}\text { Codeseira: poemas } \\
\text { 2a ed. Lugo: Ediciones Celta, } 1965\end{array}$ & Xosé Crecente Vega & Libro & Poesía \\
\hline $\begin{array}{l}\text { O clero i-o uso do idioma galego } \\
1^{\text {a }} \text { ed. Lugo: Ediciones Celta, } 1965\end{array}$ & Xosé Alvilares Moure & Libro & Ensaio \\
\hline $\begin{array}{l}\text { Lengua y estilo de Curros Enríquez (en su poesía gallega) } \\
1^{\text {a }} \text { ed. Lugo: Ediciones Celta, } 1968\end{array}$ & Xesús Alonso Montero & Libro & Ensaio \\
\hline $\begin{array}{l}\text { Poemas populares galegos } \\
1^{\text {a }} \text { ed. Lugo - Madrid: Ediciones Celta, } 1968\end{array}$ & Manuel Rodríguez López & Libro & Poesía \\
\hline 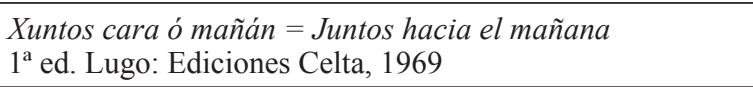 & Xesús Rábade Paredes & Libro & Poesía \\
\hline $\begin{array}{l}\text { Os cen mellores poemas da lingua galega } \\
1^{\text {a }} \text { ed. Lugo: Ediciones Celta, } 1969 \\
2^{\text {a }} \text { ed. Lugo: Ediciones Celta, } 1971 \\
3^{\text {a }} \text { ed. Lugo: Ediciones Celta, } 1972 \\
4^{\text {a }} \text { ed. Lugo: Ediciones Celta, } 1975 \\
\end{array}$ & $\begin{array}{l}\text { Xesús Alonso Montero } \\
\text { (sel.) }\end{array}$ & Libro & Poesía \\
\hline $\begin{array}{l}\text { Itinerario galego: (viaxe dun arxentino polas terras, polas } \\
\text { xentes e pola cultura de Galicia) } \\
1^{\mathrm{a}} \mathrm{ed} \text {. Lugo: Ediciones Celta, } 1970\end{array}$ & Víctor Luis Molinari & Libro & Narrativa \\
\hline
\end{tabular}

Tabela 1. Produción editorial en lingua galega: Ediciones Celta 


\begin{tabular}{|c|c|c|c|}
\hline Obra & Autoría & Tipo & Xénero \\
\hline $\begin{array}{l}\text { Saudade no bulleiro } \\
1^{\text {a }} \text { ed. Lugo: Ediciones Celta, } 1970\end{array}$ & Manuel Rodríguez López & Libro & Poesía \\
\hline $\begin{array}{l}\text { Espantallo amigo } \\
1^{\mathrm{a}} \text { ed. Lugo: Ediciones Celta, } 1971\end{array}$ & Xosé Neira Vilas & Libro & Narrativa \\
\hline $\begin{array}{l}\text { Pra vós } \\
1^{\text {a }} \text { ed. Lugo: Ediciones Celta, } 1971\end{array}$ & Fiz Vergara Vilariño & Libro & Poesía \\
\hline $\begin{array}{l}\text { Galicia: ano } 1970 \\
1^{\text {a }} \text { ed. Lugo: Ediciones Celta, } 1971\end{array}$ & & Libro & Ensaio \\
\hline 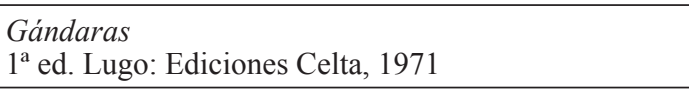 & Xosé Vázquez Pintor & Libro & Poesía \\
\hline $\begin{array}{l}\text { Os soños na gaiola } \\
2^{\mathrm{a}} \text { ed. Lugo: Ediciones Celta, } 1972 \\
3^{\mathrm{a}} \text { ed. Lugo: Ediciones Celta, } 1972\end{array}$ & Manuel María & Libro & Poesía \\
\hline $\begin{array}{l}\text { Refrás da nosa xente } \\
1^{\mathrm{a}} \text { ed. Lugo: Ediciones Celta, } 1972\end{array}$ & Xesús Alonso Montero (coord.) & Libro & Outro \\
\hline $\begin{array}{l}6 \text { novas voces das letras galegas } \\
1^{\mathrm{a}} \text { ed. Lugo: Ediciones Celta, } 1972\end{array}$ & $\begin{array}{l}\text { B. Pin Diaz / F. Vergara Vilariño / } \\
\text { F. Campos / C. Rábade / X. Rodrí- } \\
\text { guez Barrio / M. Blanco Rábade }\end{array}$ & Libro & Poesía \\
\hline $\begin{array}{l}\text { Declaración dos dereitos do neno e outras cousas nosas } \\
1^{\text {a }} \text { ed. Lugo: Ediciones Celta, } 1973\end{array}$ & & Libro & Outro \\
\hline $\begin{array}{l}\text { Os mil e un refráns galegos da muller } \\
1^{\text {a }} \text { ed. Lugo: Ediciones Celta, } 1973\end{array}$ & Xosé Moreiras Santiso (recomp.) & Libro & Outro \\
\hline $\begin{array}{l}\text { Guía informativa lucense } \\
1^{\mathrm{a}} \text { ed. Lugo: Ediciones Celta, } 1973\end{array}$ & & Libro & Outro \\
\hline $\begin{array}{l}\text { Pranto irmán } \\
1^{\text {a }} \text { ed. Lugo: Ediciones Celta, } 1973\end{array}$ & Xavier Rodríguez Barrio & Libro & Poesía \\
\hline $\begin{array}{l}\text { Apalpando o esilio da raza } \\
1^{\mathrm{a}} \text { ed. Lugo: Ediciones Celta, } 1974\end{array}$ & Xavier Rodríguez Barrio & Libro & Poesía \\
\hline $\begin{array}{l}\text { Prosas recuperadas, I: (1912-1950) } \\
1^{\mathrm{a}} \text { ed. Lugo: Ediciones Celta, } 1974\end{array}$ & Alfonso Daniel R. Castelao & Libro & Narrativa \\
\hline $\begin{array}{l}\text { Verbas violentas na dor da concencia } \\
1^{\mathrm{a}} \text { ed. Lugo: Ediciones Celta, } 1974\end{array}$ & Xavier Rodríguez Barrio & Libro & Poesía \\
\hline $\begin{array}{l}\text { Os nosos poemas } \\
1^{\text {a }} \text { ed. Lugo: Ediciones Celta, } 1974\end{array}$ & Nenos da Escola Rosalía de Castro & Libro & Poesía \\
\hline $\begin{array}{l}\text { O Ferreiro de Santán; Taberna sen dono: teatro galego } \\
2^{\mathrm{a}} \text { ed. Lugo: Ediciones Celta, } 1975\end{array}$ & Manoel D.Varela Buxán & Libro & Teatro \\
\hline 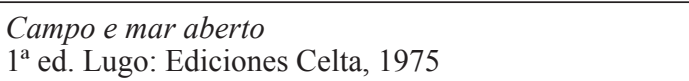 & Dora Vázquez Iglesias & Libro & Narrativa \\
\hline
\end{tabular}

Tabela 1 (cont.). Produción editorial en lingua galega: Ediciones Celta

Glicerio Albarrán Puente -que se atopaba expedientado polo franquismo-, Lugo monumental y artístico de Narciso Peinado ou Lugo y sus hombres de Salvador Castro Freire.

Porén, Francisco Esteban era un home ao que "lle tiraba o dente a literatura" e, xa en
1952, Celta edita os Contos en cuarto crecente, de Manuel María, a primeira publicación en galego da editorial. O poeta de Outeiro de Rei vai publicar en Celta unha parte considerábel da súa obra: Terra Cha, no 1954 (tamén a 3 ${ }^{\text {a }}$ ed. en 1972), Documentos persoaes, no 1958

\footnotetext{
${ }^{4}$ Esta expresión tomámola de Saleta Goi (entrevista inédita, 22/11/2014).
} 
( $2^{\mathrm{a}}$ ed. en 1970) e Libro de pregos en 1962 , ano en que tamén sairá na editorial lucense unha $2^{\mathrm{a}}$ edición corrixida e aumentada de Contos en cuarto crecente. Seu é tamén outro dos libros de maior suceso editorial na altura, o poemario infantil Os soños na gaiola que, se ben foi inicialmente publicado en 1968 por Cartonaxes Anmi, é reeditado dúas veces por Celta en 1972, xa como edición comercial.

Durante a década de 50 a editorial continuará coas súas publicacións lexislativas, mais irá engadindo títulos de notábel interese para a historia das nosas letras, como a Contribución ao estudo das fontes literarias de Rosalía, de Carballo Calero en 1959. Ao tempo, Ediciones Celta vai sacando outro tipo de publicacións, do tipo almanaques e guías turísticas, como a da propia cidade de Lugo tamén en 1959.

No curso 1960-61 chega a Lugo como catedrático de Literatura do Instituto Masculino Xesús Alonso Montero, e a Libraría e Editora Celta vaise converter nun dos centros de acción do profesor. El mesmo recoñeceu recentemente que foi en Celta onde tomou contacto por vez primeira coa imprenta e coa linotipia 5 . Segundo o seu testemuño, en Ediciones Celta non había director, nin consello asesor (eran o propietario, Francisco Esteban e o seu fillo Paulino, os que se ocupaban de todo), mais si foi evidente que el exercería de asesor, ou case de director, nos anos que pasou na cidade da muralla (1960-1976). Unha ollada ao catálogo da editorial neses anos vai iluminar á perfección o que acabamos de indicar. En 1962 encargouse Alonso Montero da publicación, cun limiar seu, da segunda edición de Retrincos de
Castelao, con gravados de Maside, e ao ano seguinte publicará nesta editora o seu primeiro libro lucense, La palabra en la realidad, mais tamén será o editor literario e responsábel da aparición doutras moitas obras en Celta: Textos literarios sobre Lugo y su provincia (1963), O clero i-o uso do idioma galego, de Alvilares Moure (1965), ou a conferencia de Castelao na Habana, Galicia y Valle-Inclán (1971). Antes, en 1969, publica en Ediciones Celta unha das súas obras máis vendidas, Os cen mellores poemas da lingua galega, unha antoloxía que tivo moi boa acollida de público e chegou ás catro edicións en 1975. Foi tamén por iniciativa de Alonso Montero que xurdiu a publicación das Prosas recuperadas de Castelao en 1974.

Ao tempo, foron numerosos os libros de interese que viron a luz grazas a Ediciones Celta: os poemarios de Luis Pimentel Barco sin luces (1960) e Arcadio López-Casanova, Hombre último (1961) ou Itinerario galego (Viaxe dun arxentino polas terras, polas xentes e pola cultura de Galicia) de Víctor Luis Molinari, traducido por Xosé Neira Vilas e Arturo Reguera, con deseño nas capas de Isaac Díaz Pardo, en 1970. Outro libro fundamental para as nosas letras editado por Celta en 1963 foi Palabras no tempo, de María Mariño.

Por último, débese ter en conta que, en moitos dos libros, Ediciones Celta aparece con sede en Lugo-Madrid pois, nun momento dado, e co obxectivo de vender todos os libros que editaban de lexislación estatal, abriron oficina en Madrid para teren así mellores posibilidades de venda e distribución; con todo, a sede editorial mantíñase na Rúa de San Marcos de Lugo ${ }^{6}$.

\footnotetext{
${ }^{5}$ Entrevista realizada na RAG o 19/12/2013 (en http://ediciongaliciafranquista.udc.es/entrevistas/6).

${ }^{6}$ Cuestión diferente é a historia de Celta de Vilagarcía da Arousa. A finais de 1938, Severino González Lazán, encargado da Imprenta Celta de Lugo, establécese nesta vila para organizar unha delegación da mesma, por encargo de Francisco Esteban, que se vai chamar tamén Imprenta Celta. Porén, axiña se independiza da de Lugo, aínda que mantén o nome. Posteriormente será tamén libraría e vai seguir funcionando como tal até 1996. O nome de Ediciós Celta aparece no pé de imprenta dos poemarios Cómaros verdes (1947), De dia a día (1960) e Leva o seu cantare (1964), de Aquilino Iglesia Alvariño, daquela profesor no colexio León XIII de Vilagarcía; non obstante, resulta evidente (e así o constatamos nunha entrevista co fillo do fundador) que Celta de Vilagarcía só funcionaba como imprenta e libraría, sendo só ocasional o seu labor como editora, ao publicar obras que eran edicións de autor, como tantas veces acontecía con libros editados nesa época.
} 
Pódese concluír, pois, que, aínda sen ter unha liña editorial claramente definida, cómpre recoñecer o meritorio labor de Ediciones Celta nos anos do franquismo na difusión da cultura galega e na visualización dalgúns dos nosos autores máis senlleiros, algúns deles (e véxase o caso relevante de Manuel María) sen posibilidade real de publicaren noutras editoriais ${ }^{7}$.

2.2. IMPRENTAS E LIBRARÍAS: GRÁFICAS BAO, ARTES GRÁFICAS GERARDO CASTRO, IMPRENTA EDITORIAL PALACIOS, IMPRENTA ALVARELLOS, IMPRENTA-LIBRARÍA LA VOZ DE LA VERDAD

Para alén da propia Celta, varias foron as imprentas que funcionaron na cidade de Lugo durante o período que estamos a analizar. En todas elas, o groso da produción foron libros editados en español, se ben tamén imprimiron algúns libros en galego. Ao igual que aconteceu noutras cidades e vilas da Galiza, o seu labor foi de especial relevancia pois propiciaron as "edicións de autor”, numerosísimas ao longo desta etapa $^{8}$. Imos, pois, revisar brevemente a actividade editorial dalgunha das máis relevantes.

\section{Gráficas Bao}

Fundada en 1952, segue a funcionar como imprenta a día de hoxe. Durante o período 1939-1975 publica trinta e cinco libros, dos cales seis son en lingua galega (véxase Tabela 2). En moitos casos aparece só como impresora, pois é outra entidade quen consta como editora (desde a Academia Alvarellos ao Círculo das Artes, pasando por la Caja de Ahorros Provincial de Lugo, por exemplo); porén, non figura editor en catorce dos volumes publicados (dous deles en galego).

\section{Artes Gráficas Gerardo Castro}

Este importante taller gráfico que funcionou desde o finais do XIX sen interrupción, edita durante este período dezaoito libros, dos cales tres son en lingua galega (véxase Tabela 3).

Do conxunto das súas publicacións, seis delas están editadas polo Concello de Lugo, que van desde programas de festas de San Froilán (1942), pasando polos Orzamentos ou as

\begin{tabular}{|c|c|c|c|}
\hline Obra & Autoría & Tipo & Xénero \\
\hline $\begin{array}{l}\text { Orballo ispido } \\
1^{\mathrm{a}} \text { ed. Lugo: Colección Xistral, } 1955\end{array}$ & Manuel Casado Nieto & Libro & Poesía \\
\hline $\begin{array}{l}\text { Cen Anos de Literatura Galega. Catálogo } \\
1^{\mathrm{a}} \text { ed. Lugo: Círculo das Artes (Lugo), } 1964\end{array}$ & $\begin{array}{l}\text { Xesús Alonso Montero } \\
\text { Epifanio Ramos de Castro (org.) }\end{array}$ & Libro & Outro \\
\hline $\begin{array}{l}\text { Dende o nimbo da lembranza } \\
1^{\mathrm{a}} \text { ed. Lugo: Ronsel, } 1965\end{array}$ & Xosé María Folgueira & Libro & Poesía \\
\hline $\begin{array}{l}\text { Sonetos da espranza presentida } \\
1^{\text {a }} \text { ed. Lugo: Ronsel, } 1965\end{array}$ & Arcadio López-Casanova & Libro & Poesía \\
\hline $\begin{array}{l}\text { Os meus cantares } \\
1^{\mathrm{a}} \text { ed. Lugo: s.n., } 1968\end{array}$ & Eugenio Vázquez Gundín & Libro & Poesía \\
\hline $\begin{array}{l}\text { Cantos e fábulas } \\
1^{\mathrm{a}} \text { ed. Lugo: s.n., } 1970\end{array}$ & Eugenio Vázquez Gundín & Libro & Poesía \\
\hline
\end{tabular}

Tabela 2. Produción editorial en lingua galega: Gráficas Bao

\footnotetext{
${ }^{7}$ Falando do proceso de edición de Terra Chá, conta o seu autor: "Como naqueles anos era dificilísimo editar nada en galego e servidor non era santo da devoción - do que nos decatamos anos andados- de Ramón Piñeiro, oráculo máximo de Galaxia, fixemos algunhas xestiós de publicación na emigración galega arxentina. (...) O proxecto non seguiu adiante. Por fin o dono da Celta de Lugo, o inesquecible D. Francisco Esteban -non galego de nación- tirou do seu obradoiro -como faría con moitas mais obras en galego- a primeira edición de Terra Chá" (Manuel María 1995: 37).

${ }^{8}$ Cómpre lembrar que moitas destas edicións carecían de Depósito Legal, mesmo algunhas posteriores ao 1957 , ano en que se estableceu.
} 


\begin{tabular}{|c|c|c|c|}
\hline Obra & Autoría & Tipo & Xénero \\
\hline $\begin{array}{l}\text { Nas orelas do Miño } \\
1^{\mathrm{a}} \text { ed. Lugo: s.n., } 1946\end{array}$ & Aquilino Iglesia Alvariño & $\begin{array}{l}\text { Non } \\
\text { libro }\end{array}$ & Poesía \\
\hline $\begin{array}{l}\text { Cinco pequenos poemas } \\
1^{\text {a }} \text { ed. Lugo: s.n., } 1951\end{array}$ & Manuel María & Libro & Poesía \\
\hline $\begin{array}{l}\text { Festival Luso-Hispano, I Certamen Literario del Miño } \\
\text { [originales del premio "Noriega Varela"] } \\
1^{\mathrm{a}} \text { ed. Lugo: Concello de Lugo, } 1960\end{array}$ & $\begin{array}{l}\text { Aquilino Iglesia Alvariño/ } \\
\text { Antonio Saraiva Leitao / Xosé } \\
\text { Conde }\end{array}$ & Libro & Poesía \\
\hline
\end{tabular}

Tabela 3. Produción editorial en lingua galega: Artes Gráficas Gerardo Castro

Ordenanzas municipales (1947, 1953 e 1956), até os orixinais do I Certamen literario del Miño (1960), onde podemos ver textos en galego. Sete son os libros onde aparece Gráficas Gerardo Castro tamén como responsábel editorial e, finalmente, en cinco non consta editor.

Cómpre indicar que esta imprenta é quen, desde 1889, edita O Gaiteiro de Lugo. Este popular, e vendidísimo, calendario pasa a se publicar, a partir de 1936 por iniciativa de Xosé Filgueira Valverde, integramente en galego, mantendo o monolingüísmo durante todo o franquismo. En 1963 Gerardo Castro vendeu a cabeceira a La Región que o seguiu publicando ata 1973.

\section{Imprenta Editorial Palacios}

Como é ben sabido, o nome desta imprenta está ligado a unha das experiencias editoriais máis interesantes da nosa historia literaria de preguerra, a revista Ronsel, pois nos seus talleres se imprimiron, entre 1924 e 1925, os seus seis números (para alén doutros libros de interese, como por exemplo, Señardá de Aquilino Iglesia Alvariño, en 1930). Palacios edita ou imprime durante o período 1939-1975 trece libros, catro deles en lingua galega (Tabela 4).

Como se pode apreciar, Xistral, a iniciativa editorial de Ánxel Johán e Manuel María, publicou alí cinco dos seis números que chegaron a editar (falta na listaxe Orvallo: 19491950, de Miguel Carlos Vidal, 1954, o único libro en español da colección). Editou, tamén, Cuentos de Galicia "O Tío Mingos" (1958), obra xuvenil, e único exemplo de produción narrativa, de Arcadio López-Casanova.

\section{Reprografia-Imprenta Alvarellos}

Falarmos de Alvarellos nos seus primeiros anos, supón sulagarnos na prehistoria da editorial Alvarellos, o que nos permite poder observar de perto o proceso de evolución dunha imprenta a editora, neste caso, a partir dun inicial proxecto pedagóxico.

A historia comeza coa fundación, en maio de 1963, da Academia Alvarellos ${ }^{9}$ por parte

\begin{tabular}{|c|c|c|c|}
\hline Obra & Autoría & Tipo & Xénero \\
\hline $\begin{array}{l}\text { Íntimas } \\
1^{\mathrm{a}} \text { ed. Lugo: Colección Xistral, } 1952\end{array}$ & Pura Vázquez Iglesias & Libro & Poesía \\
\hline 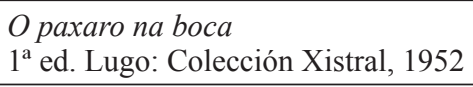 & Luz Pozo Garza & Libro & Poesía \\
\hline $\begin{array}{l}\text { Poemas pendurados de un cabelo } \\
1^{\mathrm{a}} \text { ed. Lugo: Colección Xistral, } 1952\end{array}$ & Ricardo Carballo Calero & Libro & Poesía \\
\hline $\begin{array}{l}\text { Da miña zanfona } \\
1^{\text {a }} \text { ed. Lugo: Colección Xistral, } 1954\end{array}$ & Ramón Cabanillas Enríquez & Libro & Poesía \\
\hline
\end{tabular}

Tabela 4. Produción editorial en lingua galega: Imprenta Palacios

\footnotetext{
${ }^{9}$ A Academia estaba na praza Comandante Manso, 1; esta foi a localización, tamén, da editorial, a reprografía e a imprenta.
} 
do casal formado por Henrique Alvarellos e a mestra Conchita Casas. En 1966, doce anos antes de fundar oficialmente a editora, H. Alvarellos edita o primeiro libro como Academia Alvarellos que foi o método de mecanografia da súa autoría ${ }^{10}$. Deste modo, tal como sinala o seu fillo Henrique Alvarellos Casas, a editorial naceu como unha especie de voceiro docente do que se estaba facendo na Academia (Alvarellos 2007: 9-11) e, aos poucos, vai comezando o labor de edición, primeiro sob o rótulo de Reprografía, logo Imprenta e, finalmente, Editorial Alvarellos:

A idea de ter unha editorial, o meu pai lévaa no miolo moitos anos antes de maio do 77 en que recibiu o permiso do goberno para tela (do ministro Pío Cabanillas). Dende finais dos 60 el xa estaba coa idea de activar unha editorial e, así, no ano 69 monta a Reprografía Alvarellos e nese ano publícase o volume Diversas melodías, recompilación de motetes relixiosos a cargo do Mestre de capela da catedral de Lugo, Xosé Castiñeira Pardo que será quen figure como editor. No ano 1975 a Reprografía Alvarellos convértese en Imprenta. (Entrevista inédita, 05/10/2014)

Por tanto, os volumes editados antes de 1977 correspondían, basicamente, a "propostas que ían chegando" e que logo aparecían como edicións de autor ${ }^{11}$ (Alvarellos encargábase de confeccionalos e distribuílos). Neste período, a Reprografía Alvarellos edita, sobre todo, en castelán, pois dos seis títulos publicados só hai un que se pode considerar, polo menos parcialmente, como obra en lingua galega; trátase de Las cantigas de escarnio y maldecir de Alfonso $X$, editadas polo profesor Epifanio Ramos de Castro en 1973.

\section{Imprenta-libraría La Voz de la Verdad}

La Voz de la Verdad foi o título do xornal "católico e antiliberal" que, desde 1910 a 1937, se editou en Lugo. Co mesmo nome, funcionou como imprenta e libraría vinculada ao Bispado até o presente onde, para alén desas actividades, retomou tamén o labor editorial. Durante o período 1939-1975, editou sesenta e seis libros, dos cales oito están escritos, total ou parcialmente, en lingua galega (véxase Tabela 5).

Ao igual que acontece nos casos anteriores, son numerosos os exemplos de edicións feitas polos propios autores ou autoras (cinco dos oito títulos editados en galego, vinte e seis dos cincuenta e seis en español) mesmo nalgún caso onde figura como editora a propia imprenta $^{12}$.

Por outra parte, para alén dos libros en que La Voz de la Verdad figura como editora e como imprenta, noutros figura apenas como imprenta, sendo a obra responsabilidade, ben doutra editora (como, por exemplo, Celta, no caso de La Contribución excepcional sobre

10 "No 66, meu pai escribe Mecanografía en dous meses, un manual pedagóxico para ensinar mecanografía. Ese manual tivo moitísimo éxito e, no 68, recoñeceuse como método oficial para todo o Estado. Ese foi o best-seller da editorial cando aínda non era editorial, e tivo varias edicións, primeiro como Academia Alvarellos, impreso nas históricas Gráficas Bao, e, logo, unha segunda edición nunha editorial vallisoletana. Xa no 77, cando meu pai abriu a editorial, fixo unha terceira edición, baixo o selo Alvarellos Editora" (Entrevista inédita, 05/10/2014).

11 “-E o financiamento, como era? O autor pagaba a impresión do libro? Recibía un tanto por cento polas ventas?”. “-Descoñezo como eran, pero podo deducilo. Non atopei ningún contrato anterior ao 77, así que penso que os acordos se facían de palabra, e lembro comentarios de meu pai falando de que o autor axudaba a financiar a impresión, outros levaban libros que distribuían, outros eran agasallo... Estabamos un pouco na prehistoria da industria editorial, polo menos no que atinxe a Alvarellos" (Entrevista inédita, 05/10/2014).

${ }^{12}$ Cónstanos o caso de Morrendo a cada intre, publicado "nunha edición de cativa tirada, encargada por uns amigos, pero non pagada, polo que a imprenta na que se fixo, La Voz de la Verdad, púxoo á venda para cubrir os custos da edición, que se esgotou en seis meses, segundo nos ten dito Trapero Pardo, entón responsábel da imprenta" (Gómez Torres 2011: 45). 


\begin{tabular}{|c|c|c|c|}
\hline Obra & Autoría & Tipo & Xénero \\
\hline $\begin{array}{l}\text { Non chores, Sabeliña } \\
1^{\mathrm{a}} \text { ed. Lugo: s.n., } 1943 \\
2^{\mathrm{a}} \text { ed. s.n., } 1969\end{array}$ & José Trapero Pardo & Libro & Teatro \\
\hline $\begin{array}{l}\text { D'o Ermo } \\
\text { 4 ed. aum. Lugo: s.n., } 1946\end{array}$ & Antonio Noriega Varela & Libro & Poesía \\
\hline $\begin{array}{l}\text { Morrendo a cada intre } \\
1^{\text {a }} \text { ed. Lugo: La Voz de la Verdad, } 1952\end{array}$ & Manuel María & Libro & Poesía \\
\hline $\begin{array}{l}\text { Diálogos gallegos } \\
1^{\mathrm{a}} \text { ed. Lugo: La Voz de la Verdad, } 1958\end{array}$ & & Libro & Narrativa \\
\hline $\begin{array}{l}\text { Poesías y cuentos de Galicia } \\
1^{\mathrm{a}} \text { ed. Lugo: La Voz de la Verdad, } 1962\end{array}$ & Cugasa & Libro & \\
\hline $\begin{array}{l}\text { Alalás } \\
1^{\mathrm{a}} \text { ed. Lugo: s.n., } 1972\end{array}$ & Helena Villar Janeiro & Libro & Poesía \\
\hline $\begin{array}{l}\text { Pasatempos } \\
1^{\mathrm{a}} \text { ed. Lugo: s.n., } 1972 \\
\end{array}$ & Xan de Carlos & Libro & Poesía \\
\hline $\begin{array}{l}\text { Galicia canta ó Neno: (pequena antoloxía do nadal en Galicia) } \\
1^{\text {a }} \text { ed. s.n., } 1974\end{array}$ & Xesús Mato & Libro & Outro \\
\hline
\end{tabular}

Tabela 5. Produción editorial en lingua galega: La Voz de la Verdad

beneficios extraordinarios de guerra de Rafael Alonso González en 1939, ou Ediciones del Departamento Provincial de Seminarios del Movimiento no caso de La Revolución Gallega de 1846 de Francisco J. Río Barja en 1953), ben doutras institucións, como o Mosteiro de Samos (El Padre Feijóo, su magisterio: antología de sus obras de Sara Leirós Fernández o El Padre Feijóo y su monasterio de Samos de Victoriano González, 1967), a Deputación (Guía arqueológica romana de Lugo y su provincia de Adolfo de Abel Vilela, 1975) ou o Museo Provincial (Catálogo de pintura del Museo Provincial de Lugo de $\mathrm{M}^{\mathrm{a}}$ Victoria Carballo-Calero, 1969).

\section{Outras imprentas e librarías}

Cónstanos a existencia de Gráficas Breogán, que só imprime dous libros neste período, Albre de espranza (1966), de Lois Diéguez (na colección Ronsel), e Verbas a un irmao (1970), de Darío Xohán Cabana, no que debeu ser unha edición de autor.

Por último, cómpre aínda lembrar outras librarías activas en Lugo na etapa que nos ocupa: a libraría Balmes, unha das máis antigas da Galiza, que segue en pé na rúa Progreso, hoxe en mans dos empregados, e as librarías Souto e Alonso. Esta última, se ben non chegou a editar, si foi moi activa pois nela facíanse exposicións e vendían moito libro galego ${ }^{13}$.

\subsection{CARTONAXES ANMI}

Desde unha óptica actual, a intervención desta empresa no panorama cultural lucense daqueles anos resulta certamente salientábel. Anmi non era unha editorial, nin mesmo unha imprenta senón unha pequena empresa que se dedicaba á elaboración de bandexas, caixas ou

${ }^{13}$ Ezequiel Méndez que, como é sabido, traballou de distribuidor desde a metade dos 60 até o ano 1975 sinala en varias ocasións a sorpresa que supuxo para Modesto Alonso Estravís e para el propio o número de exemplares vendidos en cidades pequenas como Ourense e Lugo, onde existían librarías que el define como moi consolidadas entre a burguesía local e que foron moi boas clientas. En concreto, en Lugo, sinala as librarías Souto e Alonso. Á pregunta: "Existía na túa opinión un público lector en galego?", responde: "Si. Sobre todo, para min, en Ourense e Lugo, había moita fidelidade ao galego" (Entrevista inédita, 05/10/2014). 
outros tipos de envoltorios que se utilizaban, tanto para a alimentación, como para roupa. $\mathrm{O}$ seu dono era o mestre socialista Ángel Gómez Camarón, habitual na tertulia do café Méndez Núñez (a dos "roxos", segundo a opinión, semella que non moi desacertada, do franquismo local...). Afirma Alonso Montero sobre el que, se ben non era nacionalista, "non descoñecía o significado antifranquista de certas manifestacións literarias en galego" (Alonso Montero 2007: 17). De feito, só baixo esa óptica do compromiso se pode interpretar que esta empresa acordase subvencionar o premio de teatro Castelao no 1965 e que, a partir de 1966, coa edición do calendario dedicado á obra Platero e mais eu, iniciase a edición de libros en galego, uns en formato almanaque ou calendario, outros como pequenos volumes, mais sempre como edicións non venais.

O eixo do calendario de $1966^{14}$ é a tradución galega de 15 capítulos de Platero y yo (realizada por R. Otero Pedrayo, S. Martínez Risco, C. Emilio Ferreiro, X. Alonso Montero,
X. L. Méndez Ferrín, Camilo G. Suárez-Llanos, Ánxel Fole, A. Núñez Domínguez, A. López Casanova, $\mathrm{M}^{\mathrm{a}}$ X. Queizán, Antía Cal, X. R. Fernández Oxea, Xohana Torres e R. Carballo Calero) e ilustrada por destacados artistas plásticos: Vázquez Díaz, I. Díaz Pardo, Mercedes Ruibal, A. Pérez Bellas, Virxilio, J. Maside, M. Colmeiro, Grandío, Blás Lourés, Manuel del Río, Laxeiro, M. Pesqueira, Xohán Ledo e Ánxel Gómez). Porén, para alén da relevancia da nómina de colaboradores, cómpre subliñar o valor simbólico das efemérides que aparecen resaltadas no calendario, produto dunha escolla, obviamente, moi intencionada: "Cartonaxes Anmi acorda subvencionar o premio de teatro "Castelao" (20/02/95); "O cardeal Martín de Herrera condena Fume de palla de Nan de Allariz" (26/06/1909); "Morre a colección Grial" (25/02/1951); "Morte de Alexandre Bóveda" (17/08/1936); "Publícase Longa noite de pedra" (15/10/1962), etc.

En 1968, Cartonaxes Anmi editou outro calendario dedicado á memoria dalgúns galegos

\begin{tabular}{|l|l|c|c|}
\hline Obra & Autoría & Tipo & Xénero \\
\hline $\begin{array}{l}\text { Calendario 1966: Platero e máis eu } \\
1^{\mathrm{a}} \text { ed. Lugo: Cartonajes ANMI, 1966 }\end{array}$ & & $\begin{array}{c}\text { Non } \\
\text { libro }\end{array}$ & Outro \\
\hline $\begin{array}{l}\text { Cantigas populares sociales: (cincuenta e nove galegas } \\
\text { e nove negras) } \\
1^{\mathrm{a}} \text { ed. Lugo: Cartonajes ANMI, 1966 }\end{array}$ & Xesús Alonso Montero (sel.) & Libro & Poesía \\
\hline $\begin{array}{l}\text { Calendario 1968 } \\
1^{\mathrm{a}} \text { ed. Lugo: Cartonajes ANMI, } 1968\end{array}$ & & $\begin{array}{l}\text { Non } \\
\text { libro }\end{array}$ & Outro \\
\hline $\begin{array}{l}\text { Homenaxe a Otero Pedrayo } \\
1^{\mathrm{a}} \text { ed. Lugo: Cartonajes ANMI, 1968 }\end{array}$ & Arcadio López-CasanovaBG & Libro & Poesía \\
\hline $\begin{array}{l}\text { Os soños na gaiola } \\
1^{\mathrm{a}} \text { ed. Lugo: Cartonajes ANMI, 1968 }\end{array}$ & Manuel María & Libro & Poesía \\
\hline $\begin{array}{l}\text { Retratos pra tempos de pouca luz. Pliegos dos amigos } \\
1^{\mathrm{a}} \text { ed. Lugo: Cartonajes ANMI, 1968 }\end{array}$ & Arcadio López-Casanova & Libro & Poesía \\
\hline $\begin{array}{l}\text { Dous contos, cinco “cousas" e mais un dibuxo inédito } \\
1^{\mathrm{a}} \text { ed. A Coruña: Cartonajes ANMI, 1970 }\end{array}$ & Alfonso Daniel R. Castelao & Libro & Narrativa \\
\hline $\begin{array}{l}\text { ¿E decímolo ou non-o decimos? } \\
1^{\mathrm{a}} \text { ed. Lugo: O Autor, } 1972\end{array}$ & Ánxel Fole & Libro & Narrativa \\
\hline $\begin{array}{l}\text { Atruxos } \\
1^{\mathrm{a}} \text { ed. Lugo: O Autor, 1974 }\end{array}$ & Xaquín Cerqueiras Puente & Libro & Poesía \\
\hline
\end{tabular}

Tabela 6. Produción editorial en lingua galega: Cartonaxes ANMI

${ }^{14}$ Pódese achar unha análise detallada desta publicación en Fernández Rodríguez (2013). 
ilustres (Castelao, Noriega Varela, Pablo Iglesias, Valle Inclán, entre outros). Nese ano, publica tamén un volume colectivo de Homenaxe a Otero Pedrayo, coordenado por Arcadio López-Casanova, e dous libros de creación de poetas mozos, mais xa cunha relevante traxectoria, un de Manuel María e outro de López-Casanova.

A vontade de ofrecer como agasallo un produto cultural de calidade, variado (tanto desde o punto de vista xenérico, como desde o formal) e, ao tempo, a carga ideolóxica e didáctica subxacente nesta iniciativa de Anmi, evidéncianse no libriño de 60 páxinas (bilingüe) que edita en 1970, Dous contos, cinco "cousas" e mais un dibuxo inédito, "para contribuír a un mellor coñecemento de Castelao", con limiar e tradución dos relatos de $\mathrm{X}$. Alonso Montero, que foi tamén quen forneceu a fotografía do debuxo inédito: "O día que saímos da nosa patria" (22/07/1940), que figura no Libro de Ouro do Centro Galego de Buenos Aires.

\section{OUTROS AXENTES E INICIATIVAS EDITORIAIS}

Neste punto semella pertinente reflectir sobre aquelas iniciativas de carácter editorial que xorden sen estaren ligadas a empresas editoras, ben impulsadas por editores a título individual, ben por entidades culturais que actuaron como patrocinadoras e/ou difusoras de actividades, eventos ou proxectos creativos.

\subsection{COLECCIÓNS XISTRAL E RONSEL}

Para comprendermos cabalmente a xénese e as características da Colección Xistral, cómpre ter presentes os seus antecedentes, isto é, a breve historia das Follas de poesía Xistral, o primeiro proxecto editorial do poeta Manuel María. Segundo relata Saleta Goi:

A creación do proxecto editorial está relacionada coa Revista Xistral, mais hai que explicar a historia desde o comezo. En 1949, dous rapaces estudantes, Manuel Antonio Sopena, fillo dunha profesora de instituto, optimista e interesado pola poesía, e Manuel María editaron na imprenta Palacios o primeiro número da revista, na que Manuel María publica versos por primeira vez. Como non pagaron á imprenta, para o número 2 acudiron á editora de Gerardo Castro, onde os dous rapaces, de 18 ou 19 anos naquela altura, tampouco pagaron. Comezaron, pois, a reclamárenlle a débeda á familia de ambos, que chegaron a un acordo e pagaron. Tempo despois, Manuel, invalidado para publicar polo caso que lle ocorrera uns anos antes e sentíndose atraído aínda pola poesía, entra en contacto con Ángel Johán, co que se xunta para comezar a publicar de novo libros de poemas, mais coa condición de que o nome do poeta non figurase en nada. Cómpre indicar que Ángel Johán xa lle fixera o limiar do seu primeiro libro de poemas Muiñeiro de Brétemas, editado en Benito Soto en 1949. (Entrevista inédita, $05 / 10 / 2014)^{15}$

Así, nesta segunda aventura editorial, reutilízase o nome (que fora unha proposta de Luis Pimentel), aínda que agora xa reconvertida en Colección, ou Cadernos de poesía, Xistral; polas razóns xa vistas, nela vai figurar só o nome de Ángel Johán, aínda que as responsabilidades corrían a cargo dos dous (López Presedo 2001: 99), nomeadamente en Manuel María o control das edicións e as xestións ante imprentas e distribuidores (Gómez Torres 2001: 42). Entre 1952 e 1955, editáronse seis títulos (cinco en galego e un en español), aínda que estaba previstos outros dous libros, un de Manuel María e outro de Mariano S. Luque. Os cinco primeiros foron publicados na Imprenta Palacios e o derradeiro en Gráficas Bao.

En concreto, os poemarios editados nesta colección foron: O paxaro na boca, Luz Pozo Garza (1952); Poemas pendurados de un cabelo, Ricardo Carballo Calero (1952); Íntimas, Pura Vázquez Iglesias (1952); Orvallo (19491950), Miguel Carlos Vidal (1953); Da miña zanfona, Ramón Cabanillas Enríquez (1954) e Orballo ispido, Manuel Casado Nieto (1955).

O propio Manuel María relata como a única axuda que tiveron para financiar este proxecto

\footnotetext{
${ }^{15}$ Sobre este asunto, véxase tamén Caño (1990: 27 e 47-49) e Gómez Torres (2001: 33-35).
} 
editorial foi a fornecida pola peña do Méndez Núñez: "Pimentel, Ricardo López Pardo e algúns outros puxeron 250 pesetas cada un. Sacouse o primeiro libro (...). Co que se xuntaba sacábase o seguinte volume. Se non chegaba, facíase outra suscrición no café. E funcionaba as'́" (Caño 1990: 48) ${ }^{15}$. E xa, para explicar o seu final, comenta: "Despois morreu, porque había uns trámites coa censura tremendos" (Caño 1990: 48).

Todo isto permítenos constatar o máis que relevante papel que a Colección de poesía Xistral cumpriu no panorama cultural da década de 50 na Galiza, como elo continuador do labor, iniciado por Benito Soto en Pontevedra, dea recuperación dunha actividade editorial sistemática en galego na posguerra ${ }^{16}$.

Outra iniciativa dinamizadora do mesmo tipo, posterior no tempo e, tal vez, con menor impacto no panorama literario do seu tempo, foi a Colección Ronsel, un nome que tamén é, obviamente, unha homenaxe ao experimento vangardista que foi a revista do mesmo nome. Subtitulada "Entregas de poesía", e creada e dirixida por Arcadio López-Casanova, na colección publícanse tres libros en galego. No derradeiro volume editado, o de Lois Diéguez, anúnciase en prensa un novo poemario de Manuel María, Acusación privada, que xa non vería a luz.

Os títulos editados foron: Dende o nimbo da lembranza, Xosé María Folgueira (1965); Sonetos da espranza presentida, Arcadio López-Casanova (1965) e Albre de espranza, Lois Diéguez (1966). Os dous primeiros aparecen impresos en Gráficas Bao e o derradeiro en Gráficas Breogán, imprenta da que só sairá outro libro máis neste período.

\subsection{CÍRCULO DAS ARTES DE LUGO}

Houbo tamén outros axentes editoriais activos na cidade durante o período, nomeadamente institucións de variado tipo (civís e relixiosas, públicas e privadas) que promoveron ou patrocinaron a edición de libros. Entre elas, cómpre citar o Círculo das Artes de Lugo pois, como é sabido, esta sociedade mantivo un activísimo labor cultural nas décadas de 50 e 60, e moi especialmente baixo a presidencia do avogado galeguista Ramón Varela Méndez, cun labor destacado a prol da cultura e a arte galegas.

Nesta etapa, organizan actividades (conferencias, exposicións..), algunha das cales tivo como consecuencia relevantes publicacións. En concreto, o Círculo edita durante este período trece libros, dos cales seis son en galego (Tabela 7). Así, cómpre citar o volume: Cen Anos de Literatura Galega, catálogo da exposición sobre o libro galego do ano 1963, baixo a coordinación de X. Alonso Montero e Epifanio Ramos de Castro.

Merecen especial mención, tamén, outros dous volumes colectivos. O primeiro foi Antonio Machado na nosa voz, formalmente unha modesta edición multicopiada de 71 páxinas publicada polo Círculo en 1966, mais cun valor político e cultural relevante na altura. $\mathrm{O}$ volume, coordinado por Alonso Montero, estaba composto por colaboracións ou traducións ao noso idioma de poemas ou textos en prosa de Antonio Machado elaboradas por "ilustres galegos". Moitos deles participaron tamén no

\footnotetext{
${ }^{15}$ Camilo Gómez Torres sinala que Manuel María conservaba entre os seus papeis unha folla autógrafa de Ánxel Johán na que figura a relación de distribuidores vendedores, ou correspondentes, e o número de exemplares achegados. Estes foron: Miguel Carlos Vidal, Ferrol (10 exemplares); Francisco Fernández del Riego, Vigo (10 ex.); X. Ramón Fernández Oxea, Madrid (10 ex.); Enrique Álvarez, Ourense (5 ex.); Libraría Souto, Lugo (5 ex.) e Librería Compostelana, Santiago (5 ex.). Figuran tamén os subscritores que inicialmente tivo a colección: Manuel Fabeiro, Noia; Carlos Herrero Álvarez, Barcelona; Antonio Arias Rodríguez, Vigo, e Ramón Couto Couto, Foz (Gómez Torres 2001: 40).

${ }_{16}$ Pouco tempo despois retómase esta iniciativa, agora baixo o nome de Editorial Xistral, con sede en Monforte, acompañando o periplo vital de Manuel María, o seu fundador. Alí, desde 1968 a 1975, publicaranse 14 libros, a maior parte dentro da Colección de poesía "Val de Lemos".
} 


\begin{tabular}{|l|l|c|c|}
\hline Obra & Autoría & Tipo & Xénero \\
\hline $\begin{array}{l}\text { Cen Anos de Literatura Galega. Catálogo } \\
1^{\mathrm{a} e d . ~ L u g o: ~ C i ́ r c u l o ~ d a s ~ A r t e s ~(L u g o), ~ 1964 ~}\end{array}$ & $\begin{array}{l}\text { Xesús Alonso Montero } \\
\text { Epifanio Ramos de Castro (org.) }\end{array}$ & Libro & Outro \\
\hline $\begin{array}{l}\text { Curso de Lingüística comparada: (Gallego-Castellano) } \\
1^{\mathrm{a}} \text { ed. Lugo: Círculo das Artes (Lugo), 1966 }\end{array}$ & Xesús Alonso Montero & Libro & Ensaio \\
\hline $\begin{array}{l}\text { Antonio Machado na nosa voz } \\
1^{\mathrm{a}} \text { ed. Lugo: Círculo das Artes (Lugo), 1966 }\end{array}$ & Xesús Alonso Montero (coord.) & Libro & \\
\hline $\begin{array}{l}\text { Terra Cha } \\
2^{\mathrm{a}} \text { ed. Lugo: Círculo das Artes (Lugo),1967 }\end{array}$ & Manuel María & Libro & Poesía \\
\hline $\begin{array}{l}\text { O porvir da lingua galega } \\
1^{\mathrm{a}} \text { ed. Lugo: Círculo das Artes (Lugo),1968 }\end{array}$ & & Libro & Ensaio \\
\hline $\begin{array}{l}\text { Muxicas no espello } \\
1^{\mathrm{a}} \text { ed. Lugo: Círculo das Artes (Lugo),1971 }\end{array}$ & Paco Martín & Libro & Narrativa \\
\hline
\end{tabular}

Tabela 7. Produción editorial en lingua galega: Círculo das Artes

segundo proxecto colectivo: O porvir da lingua galega (1968), un volume de 164 páxinas, onde colaboran X. Alonso Montero, Valentín Arias, R. Carballo Calero, B. Graña, Basilio Losada, Manuel María, V. Paz-Andrade, S. Martínez-Risco, X. L. Méndez Ferrín ou Epifanio Ramos de Castro,

Xa no ámbito da creación, a institución promoveu a segunda edición de Terra Chá de Manuel María (1967) ou Muxicas no espello de Paco Martín (1971).

\section{CONCLUSIÓNS}

Ao longo deste artigo fixemos un primeiro achegamento ao labor dos diferentes axentes editoriais activos en Lugo no período da ditadura franquista (editoras, imprentas, librarías, promotores editoriais varios...), o que nos permitiu dar conta do seu carácter heteroxéneo e, ao tempo, do dinamismo, cultural e, tamén, comercial que evidencian moitos deses axentes. Así, por exemplo, constatamos a relevancia dalgunha das editoras estudadas, cal as Ediciones Celta, por exemplo, cunha actividade moi pouco estudada até o presente.

No que atinxe á edición en galego, os exemplos presentados poden ser considerados unha boa mostra de como funcionaba este mundo, protagonizado na altura por un tipo de "activista intuitivo, utópico, empresarialmente case marxinal e fortemente ideoloxizado", tal como o expresa axeitadamente Manuel Bragado (2007: 46).

Así, pódese constatar como o conxunto de publicacións editadas na cidade de Lugo é máis extenso e variado do que, tradicionalmente, se ten considerado na nosa historiografía. É por isto que son dignos de seren salientados aspectos tales como a amplitude do catálogo dunha editora como Celta ao longo destes anos, o valor simbólico da Colección Xistral na recuperación da literatura galega na posguerra ou o papel de certas entidades e/ou empresas como dinamizadoras culturais. Todo isto permítenos (re)afirmar a idea de que o tecido editorial galego entre 1939-1975 non se circunscribiu só ás editoras mais recoñecidas e consideradas a día de hoxe como centrais no noso panorama cultural, senón que, tal como acontece noutros ámbitos (como, por exemplo, coa produción literaria do século XIX), as editoras importantes foron posíbeis porque había, tamén, un magma editorial preexistente e concomitante.

Finalmente, a actividade editorial lucense confirma, asemade, a existencia dun reducido, mais proporcionalmente relevante, público lector que se mantiña fiel ao galego, ao tempo que sustentaba unha certa actividade cultural na nosa lingua. 


\section{REFERENCIAS BIBLIOGRÁFICAS}

Alonso Montero, Xesús (2007): “O nadal nas letras galegas (1940-1979)”, Madrygal. Revista de Estudios Gallegos 10, pp. 11-33.

Alvarellos Casas, Henrique (2007): "Notas para unha historia do libro en Galicia", en H. Alvarellos Casas (coord.), Alvarellos: 30 anos de edición en Galiza. Santiago: Alvarellos, pp. 9-30.

(2014): “A edición en Lugo segundo a experiencia de Alvarellos", relatorio presentado no Seminario Edición en Galiza durante a etapa franquista. A Coruña: Universidade da Coruña, 22/01/2014 (dispoñíbel en: http://ediciongaliciafranquista.udc.es/).

Bragado, Manuel (2007): “A nosa edición contemporánea ou a emerxencia dunha industria cultural", en H. Alvarellos Casas (coord.), Alvarellos: 30 anos de edición en Galiza. Santiago de Compostela: Alvarellos, pp. 43-53.

CAÑo, José Ma del (1990): Conversas con Manuel María. Vigo: Xerais.

FERnÁNDEZ PÉREZ-SANJulián, Carme (dir.) (2014): Edición en Galiza durante a etapa franquista. A Coruña: Universidade (dispoñíbel en: http://ediciongaliciafranquista.udc.es/).

FERnÁNDEZ Rodríguez, Áurea (2013): “A tradución literaria en Galicia na ditadura (19361975), un desafío á lóxica dominante. A primeira tradución de Platero ao galego", Madrygal. Revista de Estudios Gallegos 16, pp. 31-41.

Gómez Torres, Camilo (2001): Manuel Maria: os traballos e os días. Santiago de Compostela: Laiovento.

López Presedo, Nuria (2001): Ángel Johán. Retrato dun artista (1901-1965). Textos e dibuxos inéditos. Lugo: Fundación Caixa Galicia.

Manuel María [Fernández TeIXeIro] (1995): "Como naceu o Terra Cha”, en X. Xiz (coord.), Manuel María da Terra Cha. Lugo: Citania de Publicacións, pp. 33-38.

Reboredo Pazos, Julio (2011): Por la calle de San Marcos. Biografia de una rúa lucense. Santiago: Alvarellos. 